\title{
7.
}

\section{Developing Ideation Cards for Mixed Reality Game Design}

Richard Wetzel, Tom Rodden, \& Steve Benford

Transactions of the Digital Games Research Association

2017, Vol. 3, No. 2, pp. 175-211

ISSN 2328-9422

http://todigra.org

TEXT: Licensed under Creative Commons Attribution (CC BY-

NC- ND 2.5) http://creativecommons.org/licenses/by-nc- nd/2.5/

IMAGES: All images appearing in this work are property of the respective copyright owners, and are not released into the Creative Commons. The respective owners reserve all rights.

\section{ABSTRACT}

Mixed reality games (MRGs) encompass a variety of gaming genres such as pervasive games, location-based games, and augmented reality games. They enrich the physical world with technology to create new and exciting possibilities for games - but at the same time introduce new challenges. In order to make the vast design space of MRGs easily accessible we have developed our Mixed Reality Game Cards. These 
are a deck of ideation cards that synthesize design knowledge about MRGs and enable collaborative design in a playful manner. In this paper, we describe the iterative development of the Mixed Reality Game Cards over the course of six studies. The final version of the cards constitutes a helpful tool for future designers of MRGs both for rapid idea generation as well as for more in-depth idea development. We achieve this by utilizing different types of domain-specific cards (Opportunities, Questions, Challenges) as well as promoting the inclusion of domain-extrinsic Theme cards and suggesting different rules for interacting with the cards.

\section{Keywords}

ideation cards, game design, mixed reality games, pervasive games, location-based games

\section{Introduction}

Mixed reality games (MRGs) differ from traditional videogames by combining digital elements with the real world environment. Smartphones equipped with GPS or NFC provide new forms of interactions. MRGs are often played outdoors and turn the players into their own avatars - interacting with the game world by walking or running and engaging with real world locations or objects. They include (or overlap with) other similar categories of games like location-based games, pervasive games, or augmented reality games. GeoCaching (O’Hara, 2008), Ingress (Niantic Labs, 2012), and Pokémon Go (Niantic Labs, 2016) are perhaps the three MRGs with the largest player-base. Less well-known to the general public but arguably more innovative and daring examples have been created by researchers and artists, e.g. Can You See Me Now? (Benford et al., 2006), REXplorer (Ballagas et al., 2008) or Feeding Yoshi (Bell et al., 2006). 
As a relatively new form of gaming, the reflection about, and analysis of, MRGs is still mostly limited to academic publications, e.g. (Montola et al., 2009) or (Davidsson et al., 2004). Designing such games however is not only difficult because of the rich design space MRGs offer, but also because these games raise significant new challenges. Digital content and game play needs to be embedded into real-world settings. Local conditions such as weather or traffic have to be taken into account. Spectators or bystanders might interfere or influence the game. Technologies like GPS and mobile data connectivity are unreliable and often imprecise or faulty. Other recurring themes that are relevant for MRG design include seamfulness (Chalmers and Galani, 2004), citywide performances (Benford et al., 2004), emergent behavior (Lund et al., 2010), or in-situ authoring (Weal et al., 2006).

Furthermore, MRGs are also often developed as part of interdisciplinary teams. Technology experts might know the ins and outs of how to utilize sensors. Game designers combine mechanics to create the gameplay experience. Content or location experts provide the necessary context for shaping a game around a specific place and can contribute atmosphere and theme. However, these parties do not necessarily have the same interpretation of the design space or may even be severely limited in their knowledge.

Having come across these issues repeatedly during the course of our previous research activities, we decided to tackle this problem in order to level the playing field between different stakeholders and generally make existing design knowledge easily accessible. For this, we decided to develop a deck of ideation cards specific for mixed reality games. Ideation cards have been used successfully in a wide variety of domains including game design. They foster playful and collaborative design activities, qualities that distinguish them from other collections of design knowledge such as design patterns or guidelines.

Our Mixed Reality Game Cards are a deck of 93 ideation cards that encapsulate the design space of mixed reality games. The cards utilize 
rules and formats that are inspired by other ideation card decks and combine two different approaches to support initial idea generation as well as more in-depth idea development. In this paper, we describe the iterative design process of creating these cards over the course of six studies leading to the final version of the cards. Our evaluations furthermore allow us to not only reflect on our own deck of ideation cards but also to provide valuable insight for the design of ideation cards in general. Our deck makes use of different types of domain-specific cards (Opportunities, Questions, Challenges) and combines these with domain-extrinsic Theme cards as further sources of inspiration. In addition, two rules variants for interacting with the cards are discussed that change the flow and agency of a design session giving participants a choice of which card to play or fully randomizing this aspect.

\section{Ideation Cards}

The physical properties of ideation cards make them resemble card games, and they can be classified as design games (Brandt and Messeter, 2004) (Halskov and Dalsgaard, 2006). Ideation cards possess gamelike rules ranging from the way they structure card draws, turn-taking, playing and discarding cards to randomly revealing them. They enable collaborative design in a playful atmosphere. Cards are used as orienting devices, conversation starters, and pace-makers (Hornecker, 2010).

By now ideation cards are a viable design method utilized by professional designers. The IDEO Method Cards (IDEO, 2002) are a collection of design methods that can be used as part of a design process. The IDEO Method Cards are context agnostic - they are not created to help with a specific topic but provide tools for any design scenario. Method Kit (Möller, 2012) on the other hand is not a single card deck but a collection of specific decks that cover different topics and provide themes and concepts for structuring brainstorming sessions. These two ideation decks have one interesting commonality: The cards are used as a conversation starter around a specific topic. They do not themselves 
become an element of the design. In that regard they are similar to the Deck of Lenses (Schell, 2008). The author describes 113 lenses to look through when designing a game. These lenses have been translated into a deck of ideation cards. Each card (lens) asks questions of the designer and encourages thinking about different and important aspects of their design in order for them to gain a better understanding of it. This is very similar to the approach the Exertion Cards are following (Mueller et al., 2014). Each card contains a thought-provoking suggestion and covers different elements that are crucial for exergames. When looking at these cards we can argue that they might be better suited for designers that already have a preconceived idea - their main goal is not to support the initial generation of an idea. Instead they take a more reflective approach and put a stronger emphasis on in-depth developing of an idea.

A good example of a deck that supports idea generation are PLEX Cards (Lucero and Arrasvuori, 2010). This deck consists of 22 cards that help users to create playful experiences. Each card describes a concept, e.g. nurture, fantasy, sensation, submission, thrill, or discovery. In PLEX Brainstorming a card is randomly selected while each of the two designers draws three cards. One designer starts exploring an idea based on the first card. The second designer can then choose one of their cards and extend the idea that way. Finally, the first designer does the same to finalize the idea. In PLEX Scenario designers draw three random cards and assign them as beginning, continuation, and the end, developing an idea based on these cards while doing so.

VNA cards (Kultima et al., 2008) are another example for a card-based design game. Similar to PLEX, they are used to create initial game design ideas. The VNA cards consist of three different categories that give the deck its name: red verbs, blue nouns and orange adjectives. Each of these cards contains exactly one word. Verbs can be design, bounce, grow, devote, write, or fill. Nouns include keys, fugitive, creature, estate, frosting, or flower. Examples for adjectives are empty, quite, steely, musical, rolling, or high. The whole deck consists of 240 cards with 80 cards for each category. In order to use VNA, the first designer draws a 
random verb and describes how this could be a basic idea for a game. The next person draws a noun and tries to extend the existing idea. This is repeated a third time: an adjective is used to finalize the game idea. This way VNA is used to rapidly generate several ideas for games that can then be further developed at a later stage.

As a final example, we can look at the Sound Design in Games Deck (Alves and Roque, 2011). These cards are based on a design pattern language that takes the role that sound, audio, and music play in video games (Alves and Roque, 2010). Unlike most of the aforementioned decks, the cards provide rich information on both front and back of the cards, and also point out connections between cards (as is typical for a design pattern language).

Comparing the above-mentioned decks of cards, we can conclude that while their overall goal is largely identical (supporting the design process), each deck approaches it in a different way. Examples for distinguishing elements are the amount of content, the specificity of the content, the rules for interacting with the cards, and whether the cards are more aimed at creating an initial idea or want to help explore a perhaps already-existing idea. Our research focus therefore became how to best adapt these established best practices as part of our own deck. To this end we identified the following goals for our Mixed Reality Game Cards:

- Encapsulate domain-specific design knowledge

- Foster collaboration between (multidisciplinary) teams of designers

- Avoid overwhelming (inexperienced) designers

- Avoid making (experienced) designers feel restricted

- Support initial (and rapid) generation of ideas

- Support more in-depth development of ideas 


\section{Mixed Reality Game Cards}

We developed the Mixed Reality Game Cards iteratively over the course of several studies. Our cards consist of three rather distinct types of cards: Opportunities, Questions, and Challenges. Each type has a specific function in the overall ideation process. Such a division is unusual for ideation cards - in the related work section we have seen that all other ideation cards use the same type of card. We introduced these different types to combine two different and common usages for ideation cards: creation of an initial idea (e.g. VNA, PLEX) or reflection on an idea (e.g. Deck of Lenses, Exertion Cards).

Opportunity cards describe a single concept, mechanic, or element of a mixed reality game. In an ideation session, these cards can be selected and combined to create a game design idea. They are the building blocks that describe a game. Question cards require users to answer questions in order to further define their game design idea. After an initial game design idea has been conceived they then help users to turn their (potentially) still-rough ideas into more concrete ones. Some of them are generic and could be relevant for any type of game, while others are specifically important for mixed reality games. Challenge cards are the third type of card. These describe common issues and pitfalls that can negatively affect mixed reality games. Users are encouraged to "proof" their game design ideas against these cards to see if any of the described problems might occur, and if so, how they could be prevented. The full deck of cards consists of 51 Opportunities, 18 Questions, and 24 Challenges (93 cards in total). Example cards can be seen in Figure 1 whereas Table 1 gives an overview of all cards. 


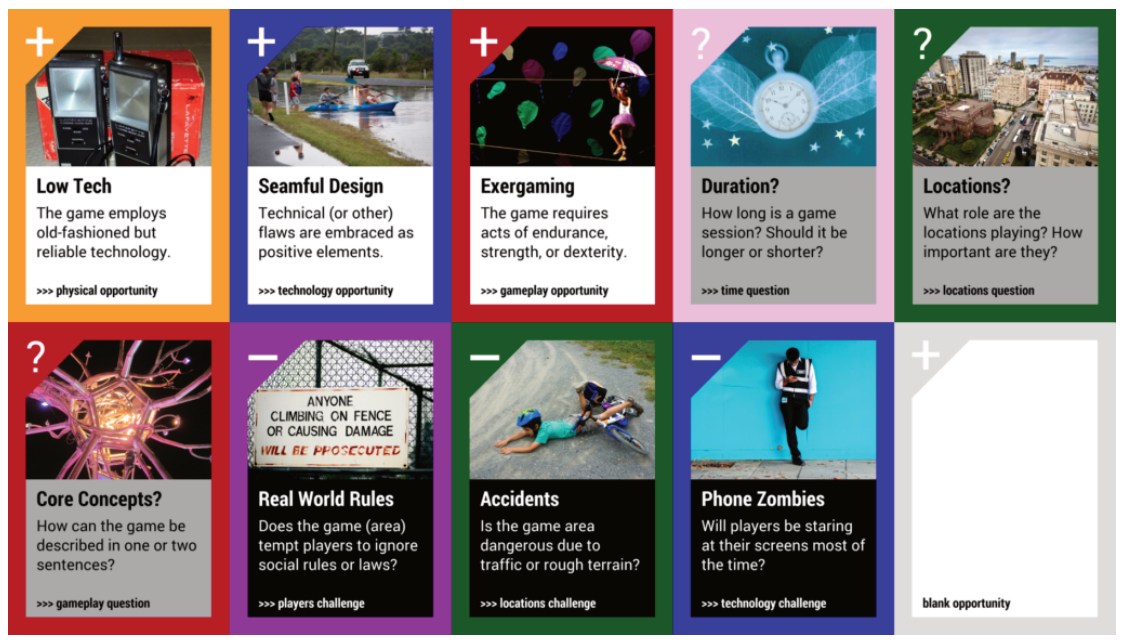

Figure 1: Final iteration of Mixed Reality Game Cards. Examples of Opportunity, Question, Challenge cards, and a blank card.

The graphical layout of all cards is identical. The upper left corner denotes the type of card (+, ?, -) which is further supported by using text on white background for Opportunities, grey background for Questions, and black for Challenges. In addition, the type of card is written at the bottom of the card. Apart from a type, each card also belongs to a category. The categories are audio, gameplay, locations, management, physical, players, sensors, technology, and time. The category is written next to the type on each card. We used color-coding based on these categories to make the cards visually more distinct and allow designers to quickly identify related cards. The actual content of a card consists of three parts. A photo takes up the upper half, followed by a title and a three-line description. The back of the cards do not contain any content and just displays the type to make sorting easier. All cards have typical playing-card size dimensions: 64 x 89mm (2.5 × 3.5 inches).

For deriving the content of the cards we used several methods. Some of the cards were created based on our personal experiences in developing mixed reality games over several years as researchers. Other cards are based on related work about specific mixed reality games or mixed 
reality game design in general (e.g. sources cited in the introduction of this paper). Lastly, observations and feedback from each study also fed back into the card deck. We do not claim that the deck is necessarily complete, however we believe that it covers a large and diverse area of the design space. The deck also includes blank cards of each type to allow designers to extend the cards with their own Opportunities, Questions and Challenges.

\section{THE RULES}

Using the Mixed Reality Game Cards can be roughly divided into three stages:

- idea generation (coming up with initial ideas)

- idea development (evolving an idea)

- idea documentation (archiving the final state of the idea).

During our studies, we used the cards in groups of three to five designers which also included some rather heterogenous groups of designers with different backgrounds and levels of experience. In general it is a good idea to sit around a table that is large enough to move cards around and form contextual groups with them on the fly, but it should also not be so big that not all designers can easily reach the cards. Pens, paper, post-its etc. are valuable additions to any design session and the Mixed Reality Game Cards are no exception. For all the processes it is important to note that the designers are free to interpret any card however they choose: They can focus on the title, a word from the description, and/or any detail on the image or what they associate it with. There is never a "wrong" interpretation of a card. 
184 ToDiGRA

\begin{tabular}{|c|c|c|c|}
\hline Category & Opportunity & Question & Challenge \\
\hline $\begin{array}{l}\text { audio } \\
\text { (yellow) }\end{array}$ & $\begin{array}{l}\text { COMPELLING AUDIO, MOBILE } \\
\text { SOUNDTRACK }\end{array}$ & & NOISE \\
\hline $\begin{array}{l}\text { gameplay } \\
\text { (red) }\end{array}$ & $\begin{array}{l}\text { AREA CONTROL, COLLECTING, } \\
\text { CREATIVITY, EXERGAMING, } \\
\text { EXPLORATION, MINI GAMES, } \\
\text { PERFORMATIVE PLAY, } \\
\text { RIDDLES, SCAVENGER HUNT, } \\
\text { STRONG NARRATIVE }\end{array}$ & $\begin{array}{l}\text { BEGINNING AND END?, } \\
\text { CHALLENGING?, CORE } \\
\text { CONCEPTS?, EXPERIENCE } \\
\text { FLOW?, FUN AND JOY?, MAIN } \\
\text { MECHANIC?, THEME AND } \\
\text { STORY? }\end{array}$ & $\begin{array}{l}\text { FEATURE CREEP, UNINTENDED } \\
\text { RACE }\end{array}$ \\
\hline $\begin{array}{l}\text { locations } \\
\text { (green) }\end{array}$ & $\begin{array}{l}\text { FITTING LOCATIONS, } \\
\text { GENERATED LOCATIONS, } \\
\text { HEADQUARTERS, SUBVERTED } \\
\text { LOCATIONS, UNUSUAL } \\
\text { LOCATIONS }\end{array}$ & $\begin{array}{l}\text { INDOOR OR OUTDOOR?, } \\
\text { LOCATIONS?, SIZE OF AREA? }\end{array}$ & $\begin{array}{l}\text { ACCIDENTS, BLAND } \\
\text { LOCATIONS, DISRUPTION, } \\
\text { DYNAMIC PLACES, GETTING } \\
\text { LOST, LONG DISTANCES, } \\
\text { OVERCROWDING, RELOCATION }\end{array}$ \\
\hline $\begin{array}{l}\text { management } \\
\text { (brown) }\end{array}$ & $\begin{array}{l}\text { OPEN AUTHORING, PUPPET } \\
\text { MASTERS }\end{array}$ & OBSERVING PLAYERS? & TESTING \\
\hline $\begin{array}{l}\text { physical } \\
\text { (orange) }\end{array}$ & $\begin{array}{l}\text { ACTORS, LOW TECH, SET } \\
\text { CONSTRUCTION, TECHNICAL } \\
\text { ARTIFACTS, USEFUL PROPS, } \\
\text { VEHICLES, WEATHER INPUT }\end{array}$ & NOTHING PHYSICAL? & RAIN AND SNOW, SUNSHINE \\
\hline $\begin{array}{l}\text { players } \\
\text { (purple) }\end{array}$ & $\begin{array}{l}\text { ALTERNATE REALITY, } \\
\text { COLLABORATION, COSTUMES, } \\
\text { DIFFERENT ROLES, ONLINE } \\
\text { PARTICIPATION, ROLEPLAYING, } \\
\text { SOCLAL CONTRACT, } \\
\text { WORLDWIDE }\end{array}$ & $\begin{array}{l}\text { NUMBER OF PLAYERS?, } \\
\text { TARGET GROUP? }\end{array}$ & $\begin{array}{l}\text { CRITICAL MASS, REAL WORLD } \\
\text { RULES, UNCLEAR } \\
\text { INSTRUCTIONS }\end{array}$ \\
\hline $\begin{array}{l}\text { sensors } \\
\text { (turquoise) }\end{array}$ & $\begin{array}{l}\text { MANUAL INTERACTION, } \\
\text { MOTION TRACKING, PASSIVE } \\
\text { TRACKING, PHYSIOLOGICAL } \\
\text { DATA, PUBLIC } \\
\text { INFRASTRUCTURE, } \\
\text { STATIONARY SENSORS, } \\
\text { WIZARD OF OZ }\end{array}$ & SUITABLE SENSORS? & INACCURATE SENSORS \\
\hline $\begin{array}{l}\text { technology } \\
\text { (blue) }\end{array}$ & $\begin{array}{l}\text { AUGMENTED REALITY, } \\
\text { GLOBAL GAMESTATE, PEER- } \\
\text { TO-PEER, PUBLIC DISPLAY, } \\
\text { SEAMFUL DESIGN, TELEPHONY, } \\
\text { TERMINALS }\end{array}$ & $\begin{array}{l}\text { GAME SERVER?. NOTHING } \\
\text { DIGITAL? }\end{array}$ & $\begin{array}{l}\text { BATTERY LIFE, CONFUSING } \\
\text { INTERFACE, GIMMICKY TECH, } \\
\text { PHONE ZOMBIES, UNENGAGING } \\
\text { AR, UNSTABLE CONNECTIVITY }\end{array}$ \\
\hline $\begin{array}{l}\text { time } \\
\text { (pink) }\end{array}$ & $\begin{array}{l}\text { EPISODIC CONTENT, TIME } \\
\text { PRESSURE, TIMED EVENTS }\end{array}$ & DURATION? & \\
\hline
\end{tabular}

Table 1: Overview of all Mixed Reality Game Cards.

\section{Idea generation}

Idea generation is the first phase of the design process. The goal is to generate several simple but intriguing game ideas in a short amount of time. In order to facilitate this use case, we combine the Opportunity cards with something we call Theme cards. These are cards that serve 
as an additional source for inspiration without any connection to mixed reality games. We suggest using surreal and/or detail-rich images and recommend repurposing cards from the board game Dixit (Roubira, 2008). Figure 2 shows some examples from the expansion Dixit Odyssey (Roubira, 2011) that were used in our studies. These cards feature dreamlike illustrations that offer multiple interpretations and as such proved to be a powerful way to spark creativity when designing games.

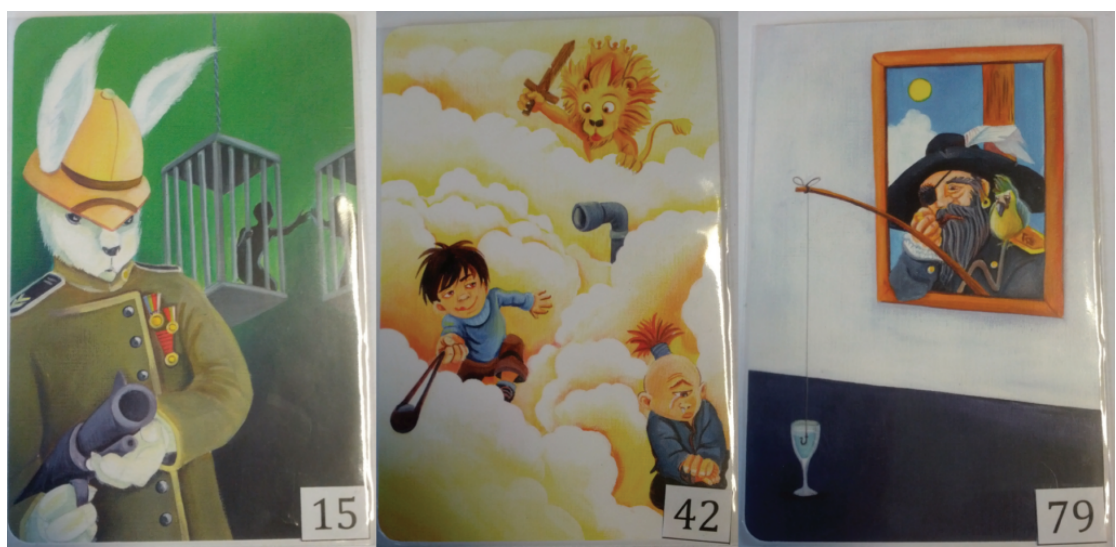

Figure 2: Example Dixit cards.

For guiding the interactions with the cards, we propose two methods that are reminiscent of PLEX Brainstorming and PLEX Scenario:

Limited choice. Each designer draws three Opportunity cards. A randomly-chosen Theme card is revealed in the center of the table. One designer places one of their cards openly next to the Theme card and describes how the two cards combine into a game idea. All designers are encouraged to discuss the proposed idea together. Then the other designers do the same and play one card into the communal area, further extending the game idea. They can either do this in turns or, depending on who has "the best" card. When as many Opportunity cards have been played as designers are participating, the final step is to agree on a game idea to write down. 
Random draw. The designers reveal three random Opportunity cards and a Theme card in the center of the table at the same time. They then jointly discuss how all four cards can be combined into one game idea - they are not allowed to ignore any of the cards. It is a good idea to enforce a time limit of around five minutes to ensure the group does not lose focus. As with the other variant, designers are encouraged to write down their game idea.

\section{Idea development}

Designers that start with idea generation can choose one of those ideas to further develop. If they already have a specific idea in mind they can also start with this stage. During idea development the designers get to use all types of cards. They start with the Opportunity cards to further flesh out their game design idea. This time they are not restricted by a card limit, and they are also encouraged to remove any cards from the table that no longer represent the game idea. In order to do so the designers each draw three cards, and then play or discard cards depending on whether they enhance the design. Designers can also draw new cards at any time or fish out a specific card if they think it is especially relevant. When they have worked on their idea in this way for a while, they can decide to continue with the next step and introduce the Question cards. The Opportunity cards stay on the table, representing the current state of the idea. However, they now draw Question cards and play them as triggers for a discussion if they believe they are helpful or crucial for their design. The Question cards should help the designers to ground their idea and turn it into something more concrete. When the designers feel that they have covered the important aspects they move on to the final step. The Challenge cards are used in the same manner as the other two types of cards. This time, however, the game idea is "proofed". The cards serve as prompts to evaluate if there are any obvious (or non-obvious) flaws or holes in the design.

Each of these steps of the idea development stage typically lasts about 30 minutes. Designers can of course extend or shorten this duration based 
on the overall flow of this stage. Likewise, they might want to go back and forth between the different steps. This is typically the case when Question or Challenge cards change the designer's perception of the game idea; adding or removing Opportunity cards lets them change the representation of the idea.

\section{Idea documentation}

The last stage of interacting with the cards is to document the final state of the idea. Designers from our studies usually found it helpful to arrange the important cards from the previous stage in a meaningful way (e.g. by forming conceptual groups). This can be done on the table itself, on a large sheet of paper, or a white board. If the cards are annotated and connections are drawn between them, they serve as a useful visual reminder of the overall game design idea (as seen in ). This should ideally not be limited to just Opportunity cards but also include Questions and Challenges that were heavily discussed or were crucial for design decisions. In addition, cards that no longer seem important should be removed to streamline the idea. This documentation stage makes sure all designers have the same understanding of the game idea (and therefore more often than not will spark additional discussion).

\section{First Series of Studies}

When we performed our first studies, the card deck consisted of 69 different cards: 36 Opportunity cards, 13 Question cards, and 20 Challenge cards. These cards were much more text-heavy than the final iteration: Cards contained examples and additional explanations (see Figure 3). Due to being the initial version, the graphic design was also less sophisticated. Here our focus was to gain a general understanding of how the cards work together, the impressions that participants get from them, and identify obvious areas for improvement are. To this end we conducted a total of three studies with different types of participants 
and slightly different approaches to the structure of the studies. We have summarized these studies in Table 2.

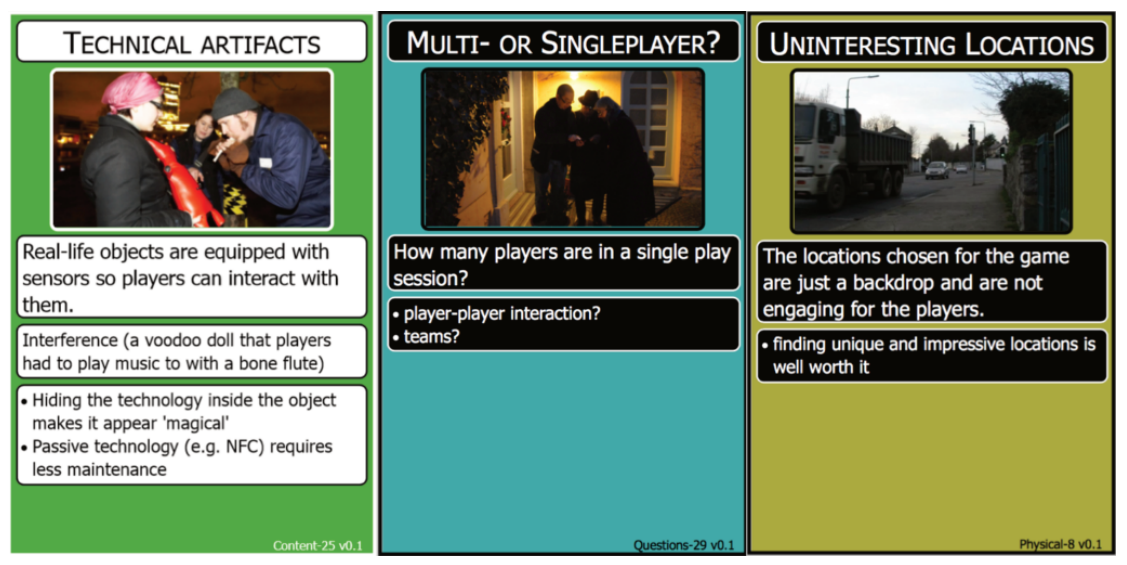

Figure 3: First iteration of Mixed Reality Game Cards.

15 bachelor students of games computing participated in this study. It was conducted as part of a two-week voluntary non-graded module on mixed reality

Study game development. Students formed four groups of three to five participants

1.1 each and utilized the cards in a total of three sessions of 25 minutes (idea generation; limited choice), and 45 and 25 minutes (idea development). After each session, participants filled in questionnaires about their experience.

As part of a research project we ran a study with 24 participants consisting of Study professionals and academics that were divided into groups of five participants.

1.2 Each group had already developed initial game ideas, and they used all types of cards to further explore their designs. The groups had one hour for idea development and afterwards completed questionnaires.

We also wanted to trial the cards with a group of inexperienced users and got this opportunity at a writer's festival. Two groups of five writers, authors and publishers participated in this study. Participants used Opportunity cards with Study no restrictions prescribing the amount of cards that could be used. The session 1.3 lasted 45 minutes, and was followed by questionnaires and a semi-structured interview.

Data collected: notes, photos, videos, questionnaires, interviews.

Table 2: Overview of studies conducted during iteration 1.

Our impressions from the first series of studies led us to believe that the cards were well received. The cards were deemed as helpful for brainstorming and fun to interact with. The collected quantitative data 
from the first three studies (Table 3) supports this impression. With open-ended questions we gave participants the ability to point out which aspects they liked and disliked. Each quote is attributed to a study and a participant in parentheses, e.g. 1.1-P5 denotes participant 5 from study 1.1 .

Positive feedback stated that the cards simplified brainstorming, broke the ice, were easily accessible, sparked creativity, and lowered the barrier for proposing ideas.

“It simplifies brainstorming and makes it more fun.” (1.1-P5)

"They allowed for good brainstorming and discussion without having to spend lots of time coming up with ideas from scratch. They helped provide a framework to build ideas off of." (1.1-P11)

“Help create discussion. Help to break the ice.” (1.2-P3)

“Makes it easy to discuss in a new way." (1.2-P15)

"All the members of the group were able to participate and add to the brainstorming." (1.2-P20)

"It was the interaction of our creative minds that was fun - the cards were the tool to enable this." (1.3-P9)

"It's easier to present ideas. It's not personal when you reject an idea.” (1.1-P10)

The main negative points concerning the cards were the graphic design (perhaps unsurprisingly) and the amount of text that was depicted on them.

"I understand the cards are in the development phase - so the visual appearance will be improved." (1.2-P20)

"Could have a nicer design to be friendlier to the eye." (1.1-P3) 
"Overload of information." (1.1-P2)

"It took some members a re-read to fully take in the meaning of the card.” (1.3-P9)

"Less information might improve interpreting the cards." (1.2-P10)

"After playing the card, everybody needed some time to read it." (1.2-P8)

"Hard to read when they were upside down." (1.3-P4)

\begin{tabular}{lllllllllll}
\hline Study & Question & 1 & 2 & 3 & 4 & 5 & AM & SD & $\mathrm{n}$ \\
1.1 & $\begin{array}{l}\text { The cards were very helpful } \\
\text { for brainstorming. }\end{array}$ & $0 \%$ & $8 \%$ & $25 \%$ & $33 \%$ & $33 \%$ & 3.92 & 0.95 & 12 \\
1.1 & $\begin{array}{l}\text { I enjoyed using the cards. } \\
1.2\end{array}$ & $0 \%$ & $0 \%$ & $25 \%$ & $33 \%$ & $42 \%$ & 4.17 & 0.8 & 12 \\
1.2 & $\begin{array}{l}\text { It was fun using the cards. } \\
\text { The Opportunity cards were }\end{array}$ & $4 \%$ & $0 \%$ & $13 \%$ & $33 \%$ & $50 \%$ & 4.25 & 0.97 & 24 \\
& $\begin{array}{l}\text { useful for brainstorming. } \\
1.2\end{array}$ & $\begin{array}{l}\text { The Question cards were } \\
\text { useful for brainstorming. }\end{array}$ & $0 \%$ & $0 \%$ & $17 \%$ & $33 \%$ & $50 \%$ & 4.33 & 0.75 & 24 \\
1.2 & $\begin{array}{l}\text { The Challenge cards were } \\
\text { useful for brainstorming. }\end{array}$ & $0 \%$ & $0 \%$ & $13 \%$ & $42 \%$ & $46 \%$ & 4.33 & 0.69 & 24 \\
$1.3 \quad \begin{array}{l}\text { Interacting with the cards } \\
\text { was fun. }\end{array}$ & $10 \%$ & $0 \%$ & $30 \%$ & $40 \%$ & $20 \%$ & 3.6 & 1.17 & 10 \\
\hline
\end{tabular}

Table 3: Questionnaire data from studies 1.1, 1.2 and 1.3. (1 = "I don’t agree"; 5 = "I agree"; AM = arithmetic mean; SD = standard deviation; $\mathrm{n}=$ number of participants)

In addition to these general observations we also noticed a potential weakness in the idea generation stage. Participants of the first study were following limited choice (selecting a card from their hand to play). While this worked well for them and they created a variety of interesting ideas, we also noticed a tendency to play a card that fit with the others. In one instance for example a participant had played 
Dominant Audio as the first card. Another participant then wanted to add Large AR to the game idea. Playing the card however was met with strong protests from the other two group members who thought such a combination “does not make sense” (1.1-P3). After a short argument, the participant withdrew the card and instead played a card that was seemingly more compatible, Peer-to-Peer. We believe the barrier to play a somewhat matching card is lower than to play one that contradicts the current idea in some ways. Our (subjective) impression was that this behaviour led to less daring ideas overall.

As an experiment, we skipped the initial idea generation stage with the participants from study 1.3. We wanted to see how an unrestricted brainstorming would develop. In both instances participants were building seemingly elaborate ideas consisting of many cards. When playing a card, a participant would introduce it with phrases like, "I think this fits really well” or "I think we should also have this element". Instead of fleshing-out an existing idea, it had the opposite effect and diluted it. During the reflection after the session the participants mentioned this aspect of the design process: "I found the cards *very* helpful as a brainstorming exercise, but moving past the purse of ideas into a more concrete concept proved difficult.” (1.3-P6) Another participant had a similar view: "The cards gave the conversation direction, but at random. I found myself getting lost, as each group member was stringing together very different thought patterns, in constant flux.” (1.3-P7) Finally, a third participant phrased it more drastically: "They encouraged us to speak in hypotheticals. They created bland, uninspired ideas.” (1.3-P10) In both cases the introduction of the Question cards seemed to work, however, the participants started to reign in their idea and rediscovered the original core of it. 


\section{Second Series of Studies}

For the next phase of studies, we created a new iteration of the cards: 44 Opportunity cards, 17 Question cards, and 21 Challenge cards made up a deck of 82 cards. Based on the experiences with the previous iteration we drastically reduced the amount of text on the cards and improved the graphic design (see Figure 4).

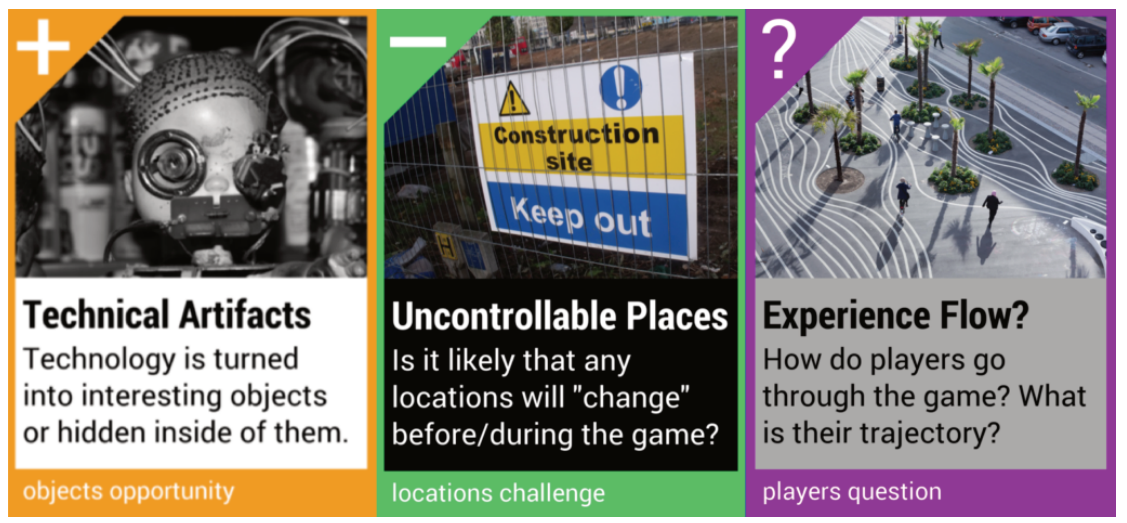

Figure 4: Second iteration of Mixed Reality Game Cards.

For the new series of studies we were especially interested in morethorough feedback concerning the split into the three different types of cards. We also wanted to find solutions for the observed problems concerning the initial idea generation step and explored the different methods to improve this phase in more detail (i.e. the aforementioned limited choice and random draw). Unlike in the previous section, we will discuss the studies separately to provide better insights into the peculiarities of each. We are doing this by providing illustrative quotes from semi-structured interviews conducted with the participants after each session. To highlight especially salient parts of their statements, we have emphasized these in bold. 
Study 2.1 - Academics, Professionals, Artists

The study was conducted with 25 academics, professionals, and artists who had previous experience with creating mixed reality games. The participants were divided into groups of five and handed the Mixed Reality Game Cards as well as instructions on how to use them. Each group started with idea generation, trying out both limited choice as well as random draw. Here, we also introduced a first version of Theme cards that consisted of single words and phrases that had some relevance for the participants: Down Under, Heaven and Hell, (Re)Distribution and Theft, GameCity, and \#gamergate. After participants had created several ideas they were told to choose one and use the remainder of their time to explore this idea in more depth with the help of the other cards. The groups spent a total of three hours with the Mixed Reality Game Cards and went on to implement their ideas in prototype form the following day.

\section{Theme Cards}

In general participants were not overly positive about the specific Theme cards we had created, but the cards did seem to influence their ideation session nonetheless: "The Theme cards were kind of... I don't think the Theme cards really helped us think of the game at all. But when we looked back we caught some theme, with the Heaven and Hell and Down Under. But that was just coincidence, I think.” (2.1-P1)

Another participant had a similar opinion: "The themes were okay. Not particularly the kind of themes I would have chosen but they were good starting points for discussion, which is what I think the purpose is." (2.1-P2)

However, another participant underlined the importance of having these cards in the first place: "I think the topics are essential for making a game jam, or making a game ideation event, because without the topic 
people would find it very difficult to come up with a game idea, so in my opinion the card set should include a number of 30 or 40 topics plus the possibility of course for the participants to create their own topics. But I would include topics into the card set.” (2.1-P6)

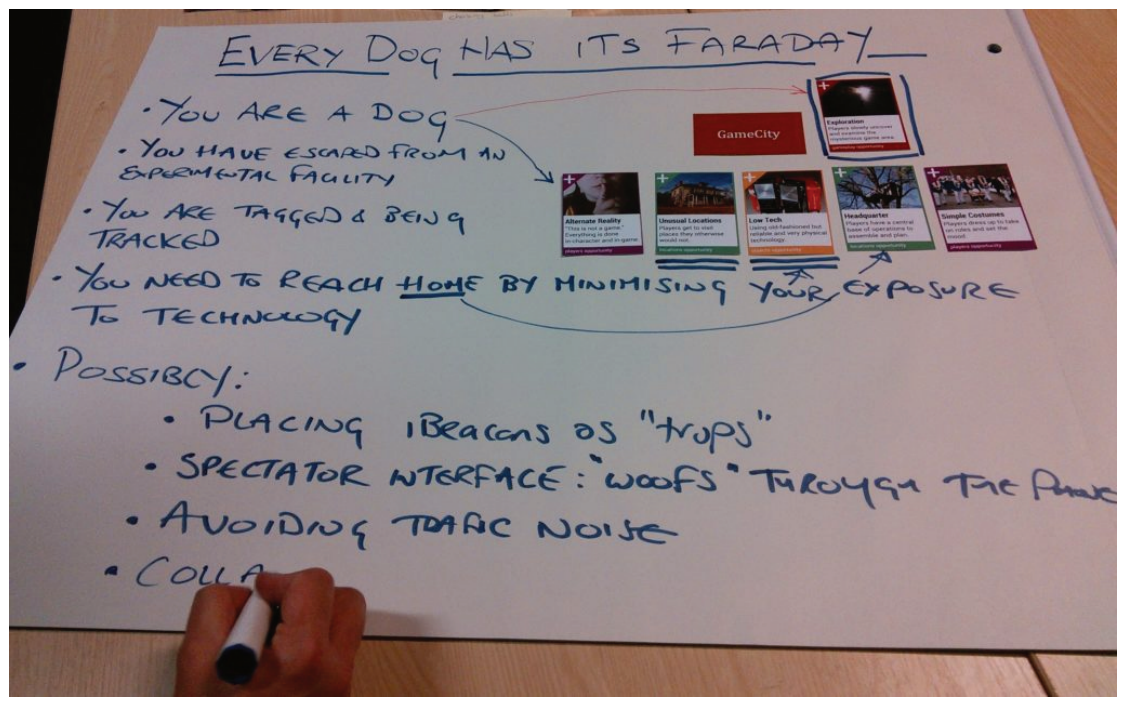

Figure 5: Game idea from study 2.1 (Every Dog Has Its Faraday).

\section{Rules}

Concerning the two variants for idea generation, we received seemingly mixed feedback. One group clearly preferred limited choice. Their argument was similar to what we observed during the previous iterations: "Somebody played Social Contract, and somebody else said 'Oh, I think User-Created Content really fits nicely to that'." (2.1-P10)

Another group member made a similar remark: "You could really sculpt out a strong connection between the cards that instantly seemed to make sense." (2.1-P11)

When asked what they perceive as the difference between the two methods, one of them described the perceived easiness when being able 
to select cards: "I feel if we can play any card we like it's much easier because I can decide what we are going to build.” (2.1-P10)

Another participant put an emphasis on the agency that comes with a choice of cards: "I think it probably works better when you've got the degree of choice because you can sort of guide it in a direction you want."

The same participant then however makes an important observation that highlights the advantage of the other variant, random draw: "But when it's just the cards down there it could turn out really brilliantly because the cards could design something for you, or give you the seeds for something really cool." (2.1-P9)

Whereas limited choice provides the participants with more agency and makes it easier for them, random draw forces them to be creative with potentially more interesting and unique outcomes. The latter is nicely illustrated by another group that designed the game Restickulous where you have to sneak a cardboard cut-out of the Eiffel Tower attached to a long stick into selfies that other people take. Here the participants attribute the design to the randomly-drawn cards (see Figure 6): "That game is exactly the three cards that we got." (2.1-P3) Another participant agrees: "We made those exact three cards into a game. We didn't deviate I guess is the thing." (2.1-P4) The previous participant explains it further: "So it was literally us thinking about those three things, and we thought it'd be funny and that's where that came from. [..] We would have never come up with that otherwise.” (2.1-P3) 


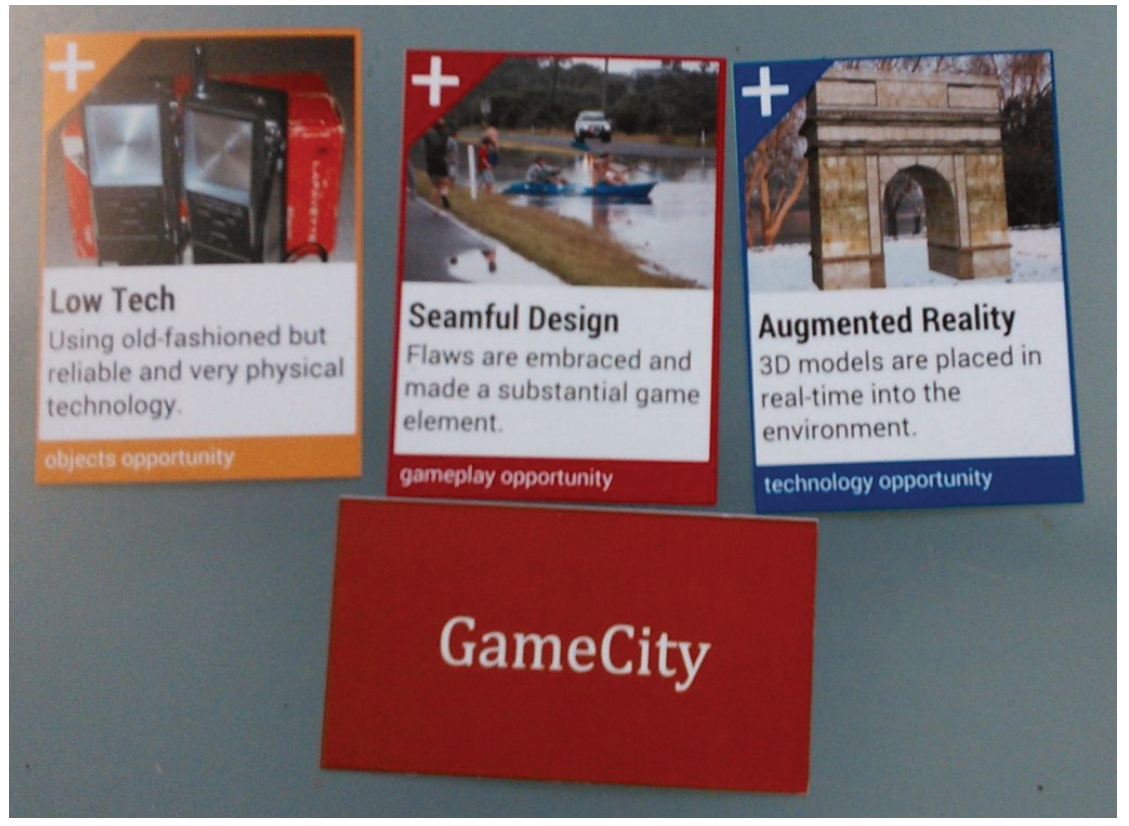

Figure 6: Cards that were the inspiration for Restickulous.

In regard to the idea development stage, a participant from another group recalled the difficulties the group had forming a coherent idea because group members kept adding Opportunity cards: "At this moment we would have needed the negative cards. To eliminate things and to ask ourselves, what are we doing? That's why the Question cards were good which then said: 'What is the core mechanic?' etc." (2.1-P6)

The Restickulous group also described their experiences with the Question cards when working on another game: "We got in a deadlock really. We couldn't figure out how to make it a game. And we were using those to try and help. It helped us work through the things.” (2.1-P3) Another participant from that group explained how the Question cards stimulated the discussion while perhaps not being directly helpful in overcoming their creative block: "I think we got to the point where we thought the card game was not working, so we pulled them out. But I don't know that they necessarily led to any changes. [..] But it's hard to 
say that's not useful in itself, because you sort of do that and you go, 'Hey, that didn't work', and the conversation flows on.” (2.1-P4) The same participant however then elaborated: "My overall feeling is the cards kind of worked. [..] The cards stopped us from going too broad and being just crazy, and helped us narrow our focus quickly. [..] Having some structure that pulls you back was really useful.” (2.1-P4)

\section{Study 2.2 - Content Experts, App Developer}

In this study we worked together with a team of four professionals: one developer of location-based applications and three members from a cultural center. The study was embedded in a bigger hackathon-like event where members of the cultural center wanted to develop a prototype for a mixed reality game to accompany a photography festival they were organizing. We used the cards on the first day in all stages over the course of 3 hours. Based on the feedback from study 2.1 we made new attempts to identify suitable Theme cards: We used both VNA cards and Dixit cards as replacements (separately from each other) while employing the random draw variant for idea generation. 


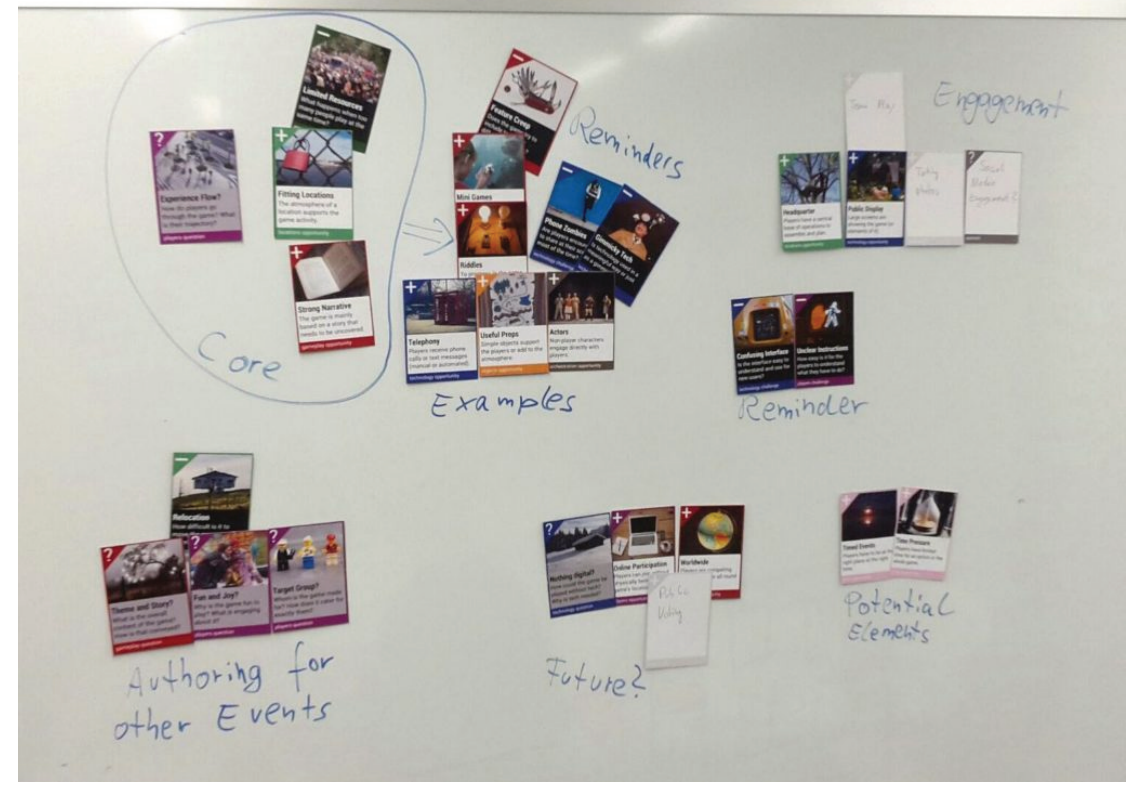

Figure 7: Final selection of cards from study 2.2.

Feedback from the participants indicated a clear preference for Dixit: "I thought the VNA cards were clever, but I didn't find them that useful. I found the Dixit cards incredible useful, because they got my creative juices flowing and made me open up a little bit and settle into the ideas. When people were talking there wasn't a lot of focus on the VNA.” (2.2-P4)

It is fair to acknowledge at this point that the VNA cards are not really designed as supporting cards. The Dixit cards however provide a rich source for additional inspiration due to them being extremely detailed and surreal. Another participant put it this way: "I think as inspiration points, specifics don't work as well as vague, kind of, you know, just think about the universe, sort of things. [..] It also allowed us to be unrestricted in our ideas and the Dixit card allowed us to think outside of the box, especially in relation to theme and its effect on the mechanics." (2.2-P2) 
When asked about the idea development stage the same participant describes the difference between the cards: "When we first started out it felt like we had a very sprawling idea, kind of, and lots of conversations about the specifics of what these things might involve. Then later on it became a much broader conversation about like 'this could be a problem for that, that, but overall it's not gonna be an issue'. You know I think we had much less specific conversations doing the questions and the negatives than we did with the positives.” (2.2-P2)

The participant then went on to illustrate this argument with an example: "Which I think is good because the positives are inspiring ideas, they are things like you said, that we didn't really think about before. You know, like coming up with the Telephony thing. Literally seeing the word telephony and thinking how would that relate to this project, immediately made me think of the voice mail thing. And that's not an idea I had previously and I wouldn't have arrived at it without having an inspiration card.” (2.2-P2)

The Opportunity cards worked as a trigger for inspiration whereas Questions and Challenges grounded the idea and allowed it to become more concrete. Figure 7 shows how they documented their final game design idea.

\section{Study 2.3 - Charity Members, Artist}

For the final study with iteration 2 of the cards, we wanted to take another look at the idea generation stage. The study participants consisted of three members of a national charity that were interested in promoting the use of public transport, bicycles, or walking by creating a mixed reality game. The group was completed by an artist who had created several location-based experiences in the past. Over the course of 45 minutes the group created six brief game ideas by using Dixit cards and the random draw rules variant. 


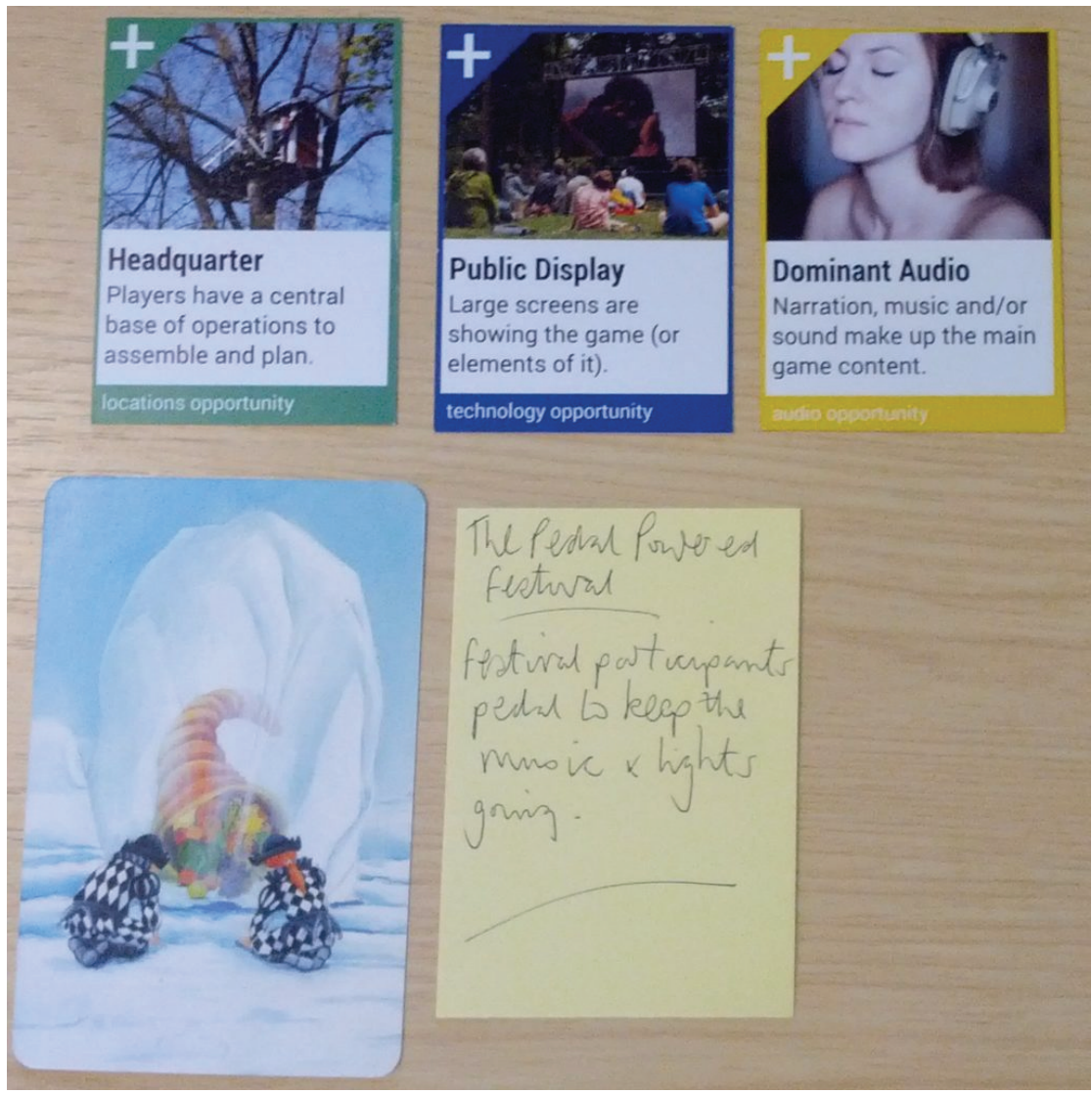

Figure 8: Game idea from study 2.3.

Perhaps unsurprisingly, the task was rather difficult for the members of the charity who had no previous experience in game design: "But frankly I found the whole thing really hard. Simply because I don't think like that. I'm not at all... It made me realize how ingrained I am in my thinking. You know. It was quite difficult to think differently." (2.3-P2)

The artist however noticed how their different perspective on things actually helped in the exercise: "I was able to copy, to some extent, what I already had in my head. Whereas I was amazed about the things that the three of you were coming up with. Which seemed much more 
original than the reference points I had in my head quite a lot of the time." (2.3-P4)

The participants were sometimes tempted to disregard one of the four cards when it did not clearly fit with the idea they had developed so far. The artist stated why doing so might not be a good idea: "Rather than saying: 'Here's three that fit and this one that doesn't', actually the creative bit is making the one that doesn't fit, fit with the three that do. And that's where the hard work comes in generally. Otherwise there's the danger that what the game becomes is just making connections between three of the four. And jettison the missing one. And that becomes the task then. Whereas actually the task should be to allow yourself to say anything. To force you almost to say something different." (2.3-P4)

Instead of discarding a difficult card, the group policed themselves as mentioned by one of the other participants: "I must admit, I found myself then in another role where I felt that the card with the stairs was gonna be discarded. I was kind of quite keen to make sure that they didn't." (2.3-P3)

The artist agrees that this was the right move: "And that worked actually for the stairs one, didn't it?"

The three charity members also reflected on the interplay between the Dixit card and the Opportunity cards (see Figure 8):

"I liked the fact that the three coloured cards with the words on them set some rules around the game. And then the picture card is revealed and then kind of takes it off." (2.3-P3)

“It's like a wild card isn't it.” (2.3-P2)

"So you read the words on the cards, for me I think the picture card adds some images, some imagery, that then takes the idea off in a way 
202 ToDiGRA

that couldn't be achieved if you just had three of the coloured cards and no strange picture card.” (2.3-P3)

\section{Design Lessons for Ideation Cards}

Over the course of six studies we observed how expert and inexperienced designers created several ideas for mixed reality games (some of which were also implemented in prototype form). A small sample of these ideas can be seen in Table 5. Ultimately, our experiences are encapsulated in the final design of the Mixed Reality Game Cards which are presented in the early sections of this paper. The cards have proven to be an effective tool to shape the collaborative design of mixed reality games. We believe that this success can be traced back to the following characteristics of the cards and rules:

- Separation of cards into Opportunities, Questions, Challenges

- Domain-extrinsic Theme cards

- Rule variants for idea generation

In the following, we will reflect on these aspects in order to share our insights with future designers of ideation cards of other domains. 
Study Players have to find NFC tags hidden at exhibits in a local museum as fast as

1.1 possible while holding their mobile phone as steady as possible. If it shakes too much, they need to go back to the starting position.

Study Players control a virtual tribe. The game world is overlaid onto the real world

1.2 and players need to provide their tribe with food etc. that they for example gather by visiting lakes.

Study Actors are dressed up as literary characters and send players on a scavenger

1.3 hunt through the city.

The players take on the role of a dog that has recently escaped from a research

Study facility and is now extremely susceptible to wireless signals. Players have to

2.1 avoid Bluetooth, Wi-Fi, and mobile connectivity and make it to freedom without getting sick from radiation (see Figure 5).

Study Players are detectives and need to visit locations of a photography festival

2.2 where they have to solve clues in order to gradually unlock a greater mystery (see Figure 7).

Study Visitors of a music festival need to use a bicycle home trainer to generate 2.3 enough energy to keep the festival going (see Figure 8).

Table 5: Sample game ideas conceived as part of the different studies.

\section{Opportunities, Questions, Challenges}

A defining element of our ideation cards is the fact that they are designed to help both in idea generation as well as idea development. We have achieved this by devising three types of cards: Opportunity cards can be used to construct a game and define its features. Question and Challenge cards on the other hand are used to make designers reflect on the current state of their design and shape the idea into a more concrete form. Opportunity cards resemble ideation cards like VNA or $P L E X$. They talk about specifics and provide the building blocks for inspiring ideas. Question and Challenge cards represent the other type of ideation cards exemplified by The Deck of Lenses and Exertion cards. They make sure to take a potentially sprawling idea and create a broader conversation about it. They help to eliminate things and let designers ask themselves 'what are we doing?' They help to narrow down an idea and keep the conversation flowing. 
These different cards are to be used in different stages of the ideation process. Opportunity cards stand at the beginning, and are the only cards (together with Theme cards, see below) that should feature during idea generation. They are also the core around which an idea is then expanded on during idea development. Question and Challenge cards turn the idea development from being constructive (as in: constructing an idea) into a more reflective activity. They highlight areas that the designers so far have not fully fleshed out, and in general provide a grounding to the idea. While such an approach is unique for ideation cards, it is reminiscent of the Six Hats method for brainstorming (De Bono, 1999). Each metaphorical hat stands for a different type of input into the brainstorming sessions as summarized in Table 6. We can argue that Opportunity cards correspond with the Green Hat whereas Challenge cards take on the role of the Black Hat. Question cards are most similar to the White Hat but not limited to the facts from before the idea was generated. Instead they let participants find the boundaries established by the idea itself. Red and Yellow Hats have no direct counterpart, but could be added as soft phases throughout the session. A Blue Hat moderator would however be very valuable. For inexperienced groups it is, for example, not easy to know when best to transition from using the Opportunity cards to the next type of card. Timing is very important in this regard - otherwise designers might be tempted to keep extending and diluting an idea by adding more and more Opportunity cards. 


\begin{tabular}{|c|c|c|}
\hline Hat & Function & Description \\
\hline Blue & Moderating & $\begin{array}{l}\text { Keeping the session on track and makes sure everyone follows } \\
\text { the guidelines. }\end{array}$ \\
\hline Green & Creativity & $\begin{array}{l}\text { Proposing new ideas, exploring alternatives, and expressing new } \\
\text { concepts. }\end{array}$ \\
\hline Yellow & Positivity & Stating just the positive elements of the current idea(s). \\
\hline White & Facts & $\begin{array}{l}\text { Describing the known elements and conditions the idea has to } \\
\text { work in/with. }\end{array}$ \\
\hline Black & Negativity & Pointing out flaws and weaknesses of the current idea(s). \\
\hline Red & Emotions & $\begin{array}{l}\text { Voicing one's feelings about the current idea(s) without having } \\
\text { to justify it. }\end{array}$ \\
\hline
\end{tabular}

Table 6: De Bono’s Six Hat method for brainstorming.

\section{Limited choice vs. random draw}

For the idea generation stage, we propose two different methods that resemble PLEX Brainstorming and PLEX Scenario. Limited choice allows designers to choose a card to play from their (limited) hand whereas random draw has them randomly reveal the cards. Participants felt more comfortable with limited choice and perceived it as being much easier. This variant provides them with agency by letting them decide which card to play. It allows them to guide the game idea in the direction they want. Designers might however be drawn to cards that fit nicely to each other and instantly make sense. With random draw on the other hand they cannot control as much whether such a strong connection can be made. From a positive perspective however, the cards could design something for you. They can be seeds for a unique idea that designers might otherwise never have come up with. This method is also much harder. It is more difficult to shape an idea out of a completely random combination, to make something that does not fit, fit. This variant requires more self-control from the designers. It would be easy to just discard a card that seems impossible to combine with the rest, but that's where the hard work comes in. It is even more required to say something different, to think differently. 
Overall, we recommend that inexperienced designers or designers unaccustomed to the design space of mixed reality games should start with the easier limited choice. This allows them to get a general understanding of the cards and can serve as a warm-up period. If there is a concrete goal for a game, this approach can also be better suited as it allows some steering of an idea. For creating ideas that are potentially more surprising and creative, the random draw variant seems to be more suited. With some discipline and a reasonable time limit, designers can rapidly go through several combinations of cards and see if one of the many ideas might be worthwhile taking further.

\section{Theme Cards}

Like our Mixed Reality Game Cards, many ideation cards feature images as part of their design. They are often added to better convey the concept of the card but also to serve an additional source of inspiration. Our approach goes a step further and adds additional Theme cards to the mix that only serve this one purpose. Theme cards are a good starting point for discussions and they arguably make it easier to come up with a game idea in the first place. We have found that Dixit cards work well for this purpose. They are overly rich in detail and thus offer several potential hooks from which an idea can be built. Good Theme cards can get the creative juices flowing and enable outside-the-box thinking. In order to work as inspiration points they need to be vague, as specifics do not work as well. Dixit cards achieve this by being extremely surreal.

This is in line with findings from a comparison of Dixit and PLEX cards as a source of inspiration for designers (Kwiatkowska et al., 2014). The authors report on the suitability of Dixit cards for such a task: "They allowed for free interpretation, making it easier for designers to find the entry points on the given card and work further with them." Whereas Opportunity cards set the rules around the game, Dixit cards play the role of wild cards that make the idea take off in often unique and unexpected ways. Without them, participants of our studies would often 
keep an idea at an abstract level - the addition of Dixit cards proved to be a great success and infused initial ideas with rich themes.

\section{Conclusions}

In this paper we have presented our Mixed Reality Game Cards physical playing cards that can be used in playful ideation sessions to generate and evolve mixed reality game ideas. We combined different approaches employed by other ideation cards and created Opportunity, Question and Challenge cards that support the design process in the idea generation as well as in the idea development stage. For idea generation, the Opportunity cards are used in conjunction with inspiring Theme cards to rapidly generate several game ideas. As part of this stage we explored two variants that result in varying levels of difficulty and potential for creativity: limited choice and random draw. During the idea development stage all cards work together to shape the game into a more concrete form thanks to thought-provoking Question and Challenge cards. The takeaways from our studies are not only applicable to this specific deck of ideation cards and mixed reality game design, but potentially also for other genres like board or video games, or specific subgenres (e.g. first-person shooters, racing games).

\section{Acknowledgements}

hile conducting the work presented in this paper, the first author was a $\mathrm{PhD}$ student at the Mixed Reality Lab of the University of Nottingham. The work was partially funded by EPSRC grant EP/I011587/1. The Mixed Reality Game Cards can be found online at https://www.pervasiveplayground.com. 


\section{Bibliography}

Alves, V., Roque, L., (2011). An inspection on a deck for sound design in games, in: Proceedings of the 6th Audio Mostly Conference: A Conference on Interaction with Sound, AM '11. ACM, New York, NY, USA, pp. 15-22. doi:10.1145/2095667.2095670

Alves, V., Roque, L., (2010). A Pattern Language for Sound Design in Games, in: Proceedings of the 5th Audio Mostly Conference: A Conference on Interaction with Sound, AM '10. ACM, New York, NY, USA, p. 12:1-12:8. doi:10.1145/1859799.1859811

Ballagas, R., Kuntze, A., Walz, S.P., (2008). Gaming Tourism: Lessons from Evaluating REXplorer, a Pervasive Game for Tourists, in: Indulska, J., Patterson, D.J., Rodden, T., Ott, M. (Eds.), Pervasive Computing, Lecture Notes in Computer Science. Springer Berlin Heidelberg, pp. 244-261. doi:10.1007/978-3-540-79576-6_15

Bell, M., Chalmers, M., Barkhuus, L., Hall, M., Sherwood, S., Tennent, P., Brown, B., Rowland, D., Benford, S., Capra, M., Hampshire, A., (2006). Interweaving mobile games with everyday life, in: Proceedings of the SIGCHI Conference on Human Factors in Computing Systems, CHI '06. ACM, New York, NY, USA, pp. 417-426. doi:10.1145/ 1124772.1124835

Benford, S., Crabtree, A., Flintham, M., Drozd, A., Anastasi, R., Paxton, M., Tandavanitj, N., Adams, M., Row-Farr, J., (2006). Can you see me now? ACM Trans Comput-Hum Interact 13, 100-133. doi:10.1145/1143518.1143522

Benford, S., Flintham, M., Drozd, A., Anastasi, R., Rowland, D., Tandavanitj, N., Adams, M., Row-Farr, J., Oldroyd, A., Sutton, J., (2004). Uncle Roy All Around You: Implicating the city in a locationbased performance. Proc Adv. Comput. Entertain. ACE 2004 21, 47. 
Brandt, E., Messeter, J., (2004). Facilitating Collaboration Through Design Games, in: Proceedings of the Eighth Conference on Participatory Design: Artful Integration: Interweaving Media, Materials and Practices - Volume 1, PDC 04. ACM, New York, NY, USA, pp. 121-131. doi:10.1145/1011870.1011885

Chalmers, M., Galani, A., (2004). Seamful interweaving: heterogeneity in the theory and design of interactive systems, in: Proceedings of the 5th Conference on Designing Interactive Systems: Processes, Practices, Methods, and Techniques, DIS '04. ACM, New York, NY, USA, pp. 243-252. doi:10.1145/1013115.1013149

Davidsson, O., Peitz, J., Björk, S., (2004). Game Design Patterns for Mobile Games. (Project report to Nokia Research Center).

De Bono, E., (1999). Six thinking hats. Taylor \& Francis.

Halskov, K., Dalsgaard, P., (2006). Inspiration Card Workshops, in: Proceedings of the 6th Conference on Designing Interactive Systems, DIS ’06. ACM, New York, NY, USA, pp. 2-11. doi:10.1145/ 1142405.1142409

Hornecker, E., (2010). Creative Idea Exploration Within the Structure of a Guiding Framework: The Card Brainstorming Game, in: Proceedings of the Fourth International Conference on Tangible, Embedded, and Embodied Interaction, TEI '10. ACM, New York, NY, USA, pp. 101-108. doi:10.1145/1709886.1709905

IDEO, (2002). IDEO Method Cards. San Francisco.

Kultima, A., Niemelä, J., Paavilainen, J., Saarenpää, H., (2008).

Designing Game Idea Generation Games, in: Proceedings of the 2008 Conference on Future Play: Research, Play, Share, Future Play '08. ACM, New York, NY, USA, pp. 137-144. doi:10.1145/ 1496984.1497007 
Kwiatkowska, J., Szóstek, A., Lamas, D., (2014). (Un)Structured Sources of Inspiration: Comparing the Effects of Game-like Cards and Design Cards on Creativity in Co-design Process, in: Proceedings of the 13th Participatory Design Conference: Research Papers - Volume 1, PDC '14. ACM, New York, NY, USA, pp. 31-39. doi:10.1145/ 2661435.2661442

Lucero, A., Arrasvuori, J., (2010). PLEX Cards: A Source of Inspiration when Designing for Playfulness, in: Proceedings of the 3rd International Conference on Fun and Games, Fun and Games '10. ACM, New York, NY, USA, pp. 28-37. doi:10.1145/1823818.1823821

Lund, K., Lochrie, M., Coulton, P., (2010). Enabling Emergent Behaviour in Location Based Games, in: Proceedings of the 14th International Academic MindTrek Conference: Envisioning Future Media Environments, MindTrek '10. ACM, New York, NY, USA, pp. 78-85. doi:10.1145/1930488.1930505

Möller, O., (2012). MethodKit. MethodKit.

Montola, M., Stenros, J., Waern, A., (2009). Pervasive Games: Theory and Design. CRC Press, USA.

Mueller, F., Gibbs, M.R., Vetere, F., Edge, D., (2014). Supporting the Creative Game Design Process with Exertion Cards, in: Proceedings of the 32Nd Annua, CHI '14. ACM, New York, NY, USA, pp. 2211-2220. doi: $10.1145 / 2556288.2557272$

Niantic Labs, (2016). Pokémon Go.

Niantic Labs, (2012). Ingress.

O’Hara, K., (2008). Understanding Geocaching Practices and Motivations, in: Proceedings of the SIGCHI Conference on Human Factors in Computing Systems, CHI '08. ACM, New York, NY, USA, pp. 1177-1186. doi:10.1145/1357054.1357239 
Roubira, J.-L., (2011). Dixit Odyssey. Libellud.

Roubira, J.-L., (2008). Dixit. Libellud.

Schell, J., (2008). The Art of Game Design: A book of lenses, 1 edition. ed. CRC Press, Amsterdam; Boston.

Weal, M.J., Hornecker, E., Cruickshank, D.G., Michaelides, D.T., Millard, D.E., Halloran, J., De Roure, D.C., Fitzpatrick, G., (2006). Requirements for in-situ authoring of location based experiences, in: Proceedings of the 8th Conference on Human-Computer Interaction with Mobile Devices and Services, MobileHCI '06. ACM, New York, NY, USA, pp. 121-128. doi:10.1145/1152215.115224 